\title{
IDENTIFICAÇÃO E ANÁLISE DOS MÉTODOS DE CUSTEIO APLICÁVEIS A UMA EMPRESA COM PRODUÇÃO TERCEIRIZADA
}

\section{IDENTIFICATION AND ANALYSIS OF COSTING METHODS FOR A COMPANY WITH OUTSOURCED PRODUCTION}

\author{
Guilherme Bergmann Borges Vieira ${ }^{1}$; Bruna Homrich Aita ${ }^{2}$; Francisco José Kliemann Neto ${ }^{3}$; Fabio \\ Chies ${ }^{4}$ \\ ${ }^{1}$ Universidade de Caxias do Sul (UCS) - Caxias do Sul - RS - Brasil \\ gbbvieir@ucs.br \\ ${ }^{2}$ Universidade Federal do Rio Grande do Sul (UFRGS) - Rio Grande do Sul - RS - Brasil \\ bruna.aita@gmail.com \\ ${ }^{3}$ Universidade Federal do Rio Grande do Sul (UFRGS) - Rio Grande do Sul - RS - Brasil \\ kliemann@producao.ufrgs.br \\ ${ }^{4}$ Universidade de Caxias do Sul (UCS) - Caxias do Sul - RS - Brasil \\ fabiochies@terra.com.br
}

\begin{abstract}
Resumo
A crescente competitividade entre as empresas impõe uma constante reavaliação de seus processos com vistas a aumentar sua eficiência e reduzir custos. Nesse contexto, a definição do método de custeio tem destacada relevância. Dada a complexidade inerente à implementação de certos métodos de custeio, antes é necessária uma análise crítica da empresa com vistas a verificar a possível adequação de cada método. Nesse contexto, o presente estudo tem como objetivo identificar os métodos de custeio indicados para uma empresa com produção terceirizada. A organização estudada atualmente utiliza o método dos Centros de Custos e, devido a algumas distorções decorrentes de seus fundamentos, deseja avaliar o possível uso de métodos alternativos de custeio. Nesse sentido, o presente artigo apresenta uma revisão dos sistemas de custos, detalhando os diferentes princípios e métodos de custeio (tradicionais e modernos) existentes, $e$ analisando sua aplicabilidade à empresa estudada. Os resultados indicam a aplicabilidade do método dos Centros de Custos, atualmente utilizado pela organização e, alternativamente, sugerem a utilização do Custeio ABC ou do TDABC para uma melhor identificação dos custos de atendimento aos diferentes clientes da empresa.
\end{abstract}

Palavras-chave: métodos de custeio; análise comparativa; empresa com produção terceirizada.

\section{Introdução}

A crescente competitividade entre as empresas impõe uma constante reavaliação de seus processos com vistas a aumentar a eficiência e reduzir custos. Para tanto, é de grande importância a mensuração dos desperdícios e das atividades que não agregam valor aos produtos, uma vez que, de posse dessas informações, é possível priorizar e dirigir esforços de melhoria aos locais onde exista maior potencial de retorno. A combinação entre o princípio e o método de custeio utilizado 
configura o sistema de custos de uma empresa (BORNIA, 2010), o qual é um ponto chave para a mensuração e gerenciamento de suas atividades, podendo gerar informações com maior ou menor detalhamento. Não existe uma só combinação adequada entre princípio e método de custeio. Tal definição deve ser analisada caso a caso e depende de uma série de fatores, tais como a composição dos custos da empresa, a diversificação de suas linhas de produtos, o horizonte de tempo a ser considerado, a capacidade técnica dos colaboradores para lidarem com soluções mais complexas e os investimentos necessários.

O presente estudo tem como objetivo identificar os métodos de custeio indicados para uma empresa com produção terceirizada. A organização atua no setor de transformados plásticos e possui estrutura enxuta, mix reduzido de produtos, simplicidade em suas operações e produção terceirizada. Atualmente, a empresa utiliza o método dos Centros de Custos. No entanto, devido a algumas distorções decorrentes dos fundamentos desse método percebidas pela organização, a mesma deseja avaliar o possível uso de métodos alternativos de custeio, especialmente os métodos ABC, TDABC e UEP, verificando se os mesmos auxiliariam a gestão de suas operações. Contudo, dada a maior complexidade inerente à implementação desses métodos, antes é necessária uma análise crítica da empresa com vistas a verificar sua possível adequação. Nesse sentido, o presente artigo apresenta uma revisão dos sistemas de custos, detalhando os diferentes princípios e métodos de custeio (tradicionais e modernos) existentes, e analisando sua aplicabilidade à empresa estudada. $\mathrm{O}$ trabalho se justifica por uma contribuição teórico-empírica, devido à discussão conceitual dos referidos métodos de custeio e à análise crítica de sua aplicabilidade à empresa em estudo.

\section{Revisão bibliográfica}

Segundo Bornia (2010), os sistemas de custos compreendem os princípios de custeio, que norteiam o tratamento das informações, e os métodos de custeio, que viabilizam a operacionalização desses princípios. De acordo com o autor, o princípio define qual informação o sistema deve gerar e está relacionado com o seu objetivo. Já o método determina como a informação será obtida e se relaciona com os procedimentos do sistema.

\subsection{Princípios de custeio}

Segundo Bornia (2010), existem três princípios básicos de custeio: i) variável; ii) variável parcial; e iii) por absorção total. Segundo Campagnolo, Souza e Kliemann Neto (2009), esses princípios tratam de modo similar a alocação dos custos variáveis aos produtos, diferenciando-se quanto à alocação dos custos fixos. Beber et al. (2004) afirmam adicionalmente que esses princípios de custeio não permitem avaliar se as perdas são realmente inerentes aos processos executados no período em análise, sendo portanto consideradas perdas normais, ou se ocorrem devido à 
ineficiência das operações, caracterizando-se como perdas anormais. Em função disso, os autores apresentam outros dois princípios de custeio: variável parcial e por absorção parcial. Esses princípios diferenciam-se dos três apresentados por Bornia (2010) pela incorporação das perdas normais aos custos dos produtos. Portanto, considerando-se conjuntamente as considerações de Bornia (2010) e de Beber et al. (2004), podem-se identificar cinco princípios de custeio: i) custeio variável; ii) custeio variável parcial; iii) custeio por absorção total; iv) custeio por absorção parcial; e v) custeio por absorção ideal.

O custeio variável considera que os custos fixos não devem ser inseridos no custo dos produtos ou serviços ofertados, sendo tratados como despesas do período. Esse princípio de custeio considera que apenas os custos variáveis incidem no custo do produto. Os defensores desse princípio de custeio afirmam que os custos fixos estão mais relacionados com a capacidade de produzir do que com o volume de produção. Portanto, qualquer rateio desses custos aos produtos é subjetivo e questionável.

Já o princípio de custeio variável parcial deriva do custeio variável, porém incorpora os custos de perdas normais provenientes de quebras, sobras, refugos e retrabalhos. Apesar de não considerar os custos fixos, ao considerar essas perdas normais, este princípio possibilita a análise dos gastos ocorridos no processo, permitindo uma visão mais detalhada e relevante na medição de perdas.

Contrariamente aos custeios variável e variável parcial, o princípio de custeio por absorção total considera que todos os custos fixos e variáveis devem ser incorporados aos produtos, inclusive as perdas. Trata-se de um princípio largamente utilizado devido a sua fácil aplicação e a sua aceitação pelo Imposto de Renda.

Derivado do custeio por absorção total, o custeio por absorção ideal aloca todos os custos, fixos e variáveis, aos produtos, exceto aqueles relacionados às perdas. Esse princípio parte do pressuposto de que o custo do produto independe do volume produzido, não sendo inseridas no custo as perdas ocorridas no período da avaliação. Esse método considera o padrão ideal, o qual dificilmente é atingido, especialmente no curto prazo (BORNIA, 2010), o que sugere a utilização de um princípio mais realista, denominado custeio por absorção parcial (BEBER et al., 2004).

O princípio da absorção parcial considera as ineficiências inerentes ao processo produtivo (perdas normais), sejam elas provenientes de refugos, ociosidade, quebras ou sobras, podendo ser utilizado em um horizonte de tempo mais curto. Trata-se do princípio de custeio que aborda o maior número de informações, uma vez que considera os custos fixos, os variáveis e as perdas normais. Logo, sua utilização possibilita uma visão mais ampla do negócio e promove uma crítica do processo. 
Cabe ressaltar que a aplicação dos princípios de custeio depende das informações que se pretendam obter. Cada organização possui processos com diferentes graus de complexidade, o que gera a necessidade de diferentes níveis de detalhamento das informações. Portanto, a escolha dos princípios de custeio deve levar em conta o grau de detalhamento necessário, pois a cada grau avançado o custo de obtenção dos dados aumenta (BORNIA, 2010). É importante salientar ainda que, como apoio à tomada de decisão, todos os princípios podem ser utilizados de modo complementar.

\subsection{Métodos de custeio}

Segundo Campagnolo, Souza e Kliemann Neto (2009), os métodos de custeio podem ser divididos em tradicionais e modernos. Tais métodos são discutidos a seguir.

\subsubsection{Métodos de custeio tradicionais}

Os métodos tradicionais compreendem o custo-padrão e o método dos Centros de Custos (CAMPAGNOLO; SOUZA; KLIEMANN NETO, 2009). De origem americana, o método do custo-padrão serve mais para controlar e acompanhar a produção do que propriamente para medir seus custos, devendo ser encarado como um instrumento de apoio gerencial (BORNIA, 2010).

Segundo Müller (1996), o custo-padrão tem como objetivo geral estabelecer medidas de comparação (padrões) concernentes à eficiência da utilização dos meios de produção e seus custos associados. Segundo o autor, são estabelecidos padrões físicos e monetários para uma produção e consumo eficientes. Basicamente, esse método é usado para a determinação dos custos variáveis que irão compor o cálculo de margem de contribuição. O foco do controle está nas variações em relação ao padrão estabelecido e a melhoria dos custos recai sobre o questionamento dos padrões.

Segundo Bornia (2010), seus procedimentos consistem, resumidamente, em: i) fixar um custo padrão, o qual servirá de referência para a análise; ii) determinar os custos realmente incorridos; iii) verificar a variação ocorrida entre o padrão e o real; e iv) analisar a variação, a fim de auxiliar a busca pelas causas dos desvios.

O custo-padrão repousa sobre o princípio do custeio parcial, pois serve como uma referência contra a qual são comparados os custos reais. Seu uso é particularmente indicado para o cálculo dos custos de matéria prima. Em casos específicos, pode ser utilizado também para os custos de mão de obra direta, como em empresas de consultoria, nas quais esse custo tem especial relevância. Já para os custos indiretos de fabricação seu uso não é indicado, uma vez que pode ser difícil identificar seus padrões (BORNIA, 2010).

Já o método dos Centros de Custos, segundo Bornia (2010), tem por finalidade alocar custos indiretos de fabricação, não sendo apropriado para custos de matéria-prima. Originou-se na 
Alemanha, no início do século XX. Conforme Knolseisen (2003), este método é o mais usado no Brasil e no mundo.

Sua principal característica reside na divisão da empresa em centros de custos com base em critérios que podem considerar o organograma, a localização de cada setor, a divisão de responsabilidades e a homogeneidade das tarefas. Quanto mais homogêneo for cada centro de custos, mais precisos serão os resultados da distribuição dos mesmos aos produtos.

O uso desse método é indicado para o cálculo dos custos indiretos de fabricação. Os custos são alocados aos centros por meio de bases de distribuição (critérios que identifiquem os custos com os centros, como por exemplo potência instalada, mão de obra utilizada etc) e repassados aos produtos por unidades de trabalho (parcela do trabalho dedicada a cada produto). Bornia (2010) classifica os centros entre diretos (aqueles que trabalham diretamente com os produtos) e indiretos (aqueles que prestam apoio aos centros diretos e à empresa como um todo). Pela dificuldade de distribuição dos centros indiretos aos produtos, inicialmente alocam-se os custos dos centros indiretos aos diretos. Portanto, as etapas de operacionalização do método são as seguintes: i) separação dos custos em itens; ii) divisão da empresa em centros de custos; iii) identificação dos custos com os centros; iv) distribuição dos custos dos centros indiretos aos diretos; e v) distribuição dos custos dos centros diretos aos produtos.

Esse método repousa sobre o princípio da absorção total, embora possa ser ajustado para o custeio parcial ou ideal, gerando, assim, dados de desperdício como ociosidade, ineficiência e retrabalho. Embora tais informações possam ser obtidas pelo método dos Centros de Custo, normalmente as mesmas carecem de precisão. Informações mais precisas podem ser obtidas com o uso do método $\mathrm{ABC}$ que apresenta um nível maior de detalhamento.

A identificação dos itens de custo existentes, o rateio desses itens por centro de custos (diretos e indiretos) e a alocação dos custos aos produtos são as principais informações gerenciais providas pelo método. Suas limitações intrínsecas referem-se à: utilização de critérios subjetivos para ratear os gastos comuns entre diferentes centros de custos; falta de detalhamento suficiente nos centros de custos (por carência de precisão); e falta de homogeneidade nas operações realizadas nos centros, gerando distorções.

\subsubsection{Métodos de custeio modernos}

Segundo Campagnolo, Souza e Kliemann Neto (2009), os métodos modernos de custeio são representados pelo Activity-Based Costing ( $\mathrm{ABC}$ ) e sua simplificação, denominada Time Driven Activity-Based Costing (TDABC), e pelo método das Unidades de Esforço de Produção (UEPs). No entanto, podem-se citar outras abordagens, tais como a Teoria das Restrições ou Theory of Contraints (TOC) de Goldratt e Cox (1984) e o modelo da Gestão Econômica (GECON) de Catelli 
(2001). Como estão baseados no custeio variável e não consideram os custos indiretos, esses dois últimos métodos não serão aprofundados no presente artigo.

$\mathrm{O}$ ABC surgiu como resposta às dificuldades encontradas nos métodos tradicionais de custeio em direcionar os custos indiretos aos produtos. Sua origem é atribuída a Cooper e Kaplan (1988) por ocasião da publicação da obra 'Mesure cost right: make the right decisions', apesar de Bornia (2010) indicar referências de que procedimentos similares já haviam sido apresentados em trabalhos anteriores.

$\mathrm{O}$ ABC pressupõe que as atividades consomem recursos e geram custos, enquanto os produtos usam tais atividades e absorvem seus custos. Trata-se de um sistema de duas fases: i) os custos são alocados às várias atividades; e ii) esses custos alocados são transferidos aos produtos através de bases que representem as relações entre as atividades e os custos decorrentes. O ABC busca sanar o déficit de precisão inerente aos sistemas tradicionais, que desconsideram os custos de complexidade (BORNIA, 2010).

Como o $\mathrm{ABC}$ parte do princípio que as atividades geram custos e que os produtos demandam tais atividades, o método as considera para criar o vínculo entre os custos indiretos e os objetos de custo, tais como produtos, linhas de produto, clientes etc. As etapas de operacionalização do método são as seguintes: i) análise dos processos e visualização em atividades; ii) compreensão do comportamento das atividades e identificação dos direcionadores de custos primários; iii) cálculo dos custos das atividades; iv) identificação dos direcionadores de custos secundários; e v) alocação dos custos aos clientes/ produtos/ serviços de forma proporcional ao seu grau de utilização dos direcionadores de custos secundários.

Percebe-se que o mapeamento das atividades, precede o custeio propriamente dito. De posse do mapeamento, é feita a distribuição dos custos indiretos às atividades (distribuição primária) e dos custos das atividades aos produtos (distribuição secundária). Com isso, a empresa terá subsídios para questionar e redesenhar os processos. Nesse ponto, já se poderia falar em Gestão Baseada em Atividades ou Activity-Based Management (ABM). Embora o ABC e o ABM sejam muitas vezes tratados como sinônimos na literatura, este último é mais amplo e incorpora o próprio $\mathrm{ABC}$.

A utilização do Custeio ABC é particularmente oportuna para as atividades indiretas (de apoio). Não haveria sentido utilizá-lo, no entanto, para atividades diretas, uma vez que os custos decorrentes das mesmas podem ser facilmente alocados aos produtos. Portanto, o ABC pode ser utilizado como alternativa ao método dos Centros de Custos.

Como o ABC apura os custos dos recursos usados nos processos de operação da empresa para fabricar produtos e a diferença entre os recursos utilizados e os disponíveis permite identificar o excesso de capacidade (KHOURY e ANCELEVICZ, 2000), percebe-se que, em sua implantação, o ABC identifica-se com o princípio da absorção ideal. No entanto, Cooper e Kaplan (1992) apud 
Khoury e Ancelevicz (2000) defenderam a utilização da capacidade prática de uma atividade como o denominador para o cálculo do seu custo unitário. Isso sugere o uso do princípio da absorção parcial (BEBER et al, 2004; CAMPAGNOLO; SOUZA; KLIEMANN NETO, 2009) na operacionalização do método, incluindo-se as perdas normais nessa capacidade.

Como crítica, percebe-se que o custeio ABC estimula a escolha por produtos padronizados, com maiores volumes e que utilizam menos atividades de suporte (KHOURY e ANCELEVICZ, 2000). Isso, segundo os autores, permite que a empresa tenha a mesma receita com uma menor quantidade de atividades desenvolvidas. No entanto, o ABC desconsidera o potencial impacto dos produtos customizados na retenção dos clientes, no valor percebido e na competitividade no longo prazo. É importante considerar que a busca por produtos padronizados e de elevado volume pode tornar a empresa parecida com os seus concorrentes e, desse modo, reduzir sua competitividade (PORTER, 1996).

O Custeio ABC pode ser considerado complementar ao método do custo-padrão, sendo este último utilizado para o cálculo dos custos diretos, especialmente os de matéria-prima, e aquele indicado para os custos indiretos. Em relação ao método dos Centros de Custos, a principal diferença ocorre devido à visão de processo ou visão horizontal da empresa proporcionada pelo Custeio $\mathrm{ABC}$, uma vez que, para a utilização do mesmo, a empresa deve ser modelada em atividades. Contrariamente, o método dos Centros de Custos está baseado em uma visão funcional ou vertical da empresa, a qual é dividida em centros de custos que muitas vezes correspondem aos próprios departamentos da organização. A principal vantagem do $\mathrm{ABC}$ em relação a método dos Centros de Custos diz respeito ao maior nível de detalhamento das atividades, o que permite uma visão mais acurada dos custos e desperdícios existentes. No caso do método dos Centros de Custos, como podem existir várias atividades heterogêneas associadas a um único centro, os resultados gerados podem apresentar distorções. Por outro lado, o mapeamento das atividades é mais complexo (e mais oneroso) do que a simples divisão da empresa em centros de custos, o que evidencia uma desvantagem do Custeio ABC.

Segundo Khoury e Ancelevicz (2000), há controvérsia na literatura especializada sobre o custeio ABC. Segundo os autores, apesar da maior acurácia alegada pelos proponentes do ABC, há opositores argumentando que nem sempre o método leva a melhores decisões empresariais. Em pesquisa entre as 500 maiores empresas do Brasil, Khoury e Ancelevicz (1999) constataram que, das 286 respondentes, somente 52 iniciaram a implantação do $\mathrm{ABC}$, sendo que duas decidiram abandoná-lo. Assim, os autores identificaram um uso não generalizado do $\mathrm{ABC}$, concluindo que sua adequação é limitada a situações específicas.

Segundo Cooper e Kaplan (1988), os objetivos a serem alcançados por um sistema de custos são os seguintes: i) avaliação dos estoques para a elaboração de relatórios financeiros e fiscais; ii) 
controle operacional, fornecendo informações sobre os recursos consumidos; e iii) apuração individual dos custos dos produtos. Segundo o autor, o método dos Centros de Custos atende satisfatoriamente bem apenas ao primeiro objetivo, não sendo muito útil para o controle operacional e não gerando uma apuração acurada dos custos individuais dos produtos. Cooper e Kaplan (1988) argumentam que o referido controle operacional é melhor atendido por medidas de produtividade e índices não financeiros, tais como taxas de defeitos, quantidades produzidas, níveis de estoques físicos, entre outros. Já o custeio individual dos produtos é o que se propõe a atender o ABC.

Visto que muitos custos indiretos estão relacionados à complexidade e não ao volume de produção (KHOURY e ANCELEVICZ, 2000; BORNIA, 2010), as bases de rateio escolhidas não devem necessariamente estar associadas ao volume de produção, mais sim às atividades.

Datar e Gupta (1994) apud Khoury e Ancelevicz (2000) identificaram erros de três tipos (de agregação, de especificação e de medição) no sistema ABC e mostraram que refinamentos como o aumento do número de atividades e de direcionadores podem aumentar o erro de custeio em virtude da interação entre os três tipos de erro. Embora o ABC diminua os erros de especificação e de agregação, comuns nos sistemas tradicionais, o mesmo tende a aumentar os erros de medição, devido à dificuldade em mensurar as atividades e ao elevado grau de subjetividade nesse processo.

Khoury e Ancelevicz (2000) apresentam três críticas principais ao Custeio ABC. A primeira refere-se ao fato de o mesmo fornecer informações sobre o passado, enquanto a administração precisa tomar decisões para gerar valor futuro. Segundo os autores, Kaplan (1992) rebateu essa crítica argumentando que o passado é importante, pois o padrão se repete; que outras ferramentas, como a Gestão da Qualidade Total ou Total Quality Management (TQM), também utilizam informações do passado; e que o ABC pode utilizar informações baseadas nos custos de reposição, nos custos orçamentários ou nos custos-meta, sendo assim uma poderosa ferramenta para fazer previsões. Mesmo que se considerem válidos esses argumentos, é importante considerar o risco de o ABC bloquear o processo de inovação nos produtos ao privilegiar a padronização e altos volumes, o que poderia influenciar negativamente a competitividade da empresa, como mencionado anteriormente. A segunda crítica refere-se ao fato de o ABC não fornecer medidas de produtividade e tempo de processo. Kaplan (1992) respondeu sugerindo que o ABC e outros sistemas que fornecem tais medidas (e que não indicam os custos) sejam usados de forma complementar. Finalmente, a terceira crítica refere-se ao fato de o ABC levar as empresas a cobrarem preços excessivamente altos para produtos específicos. Kaplan (1992) argumentou que não é possível atender a todas as necessidades de todos os clientes e que o ABC ajuda a identificar quais necessidades devem ser efetivamente atendidas.

Considerado o contexto descrito acima, pode-se perceber que o custeio ABC busca resolver alguns problemas relacionados à inadequação da aplicação dos sistemas de custeio tradicionais aos 
processos de manufatura da atualidade (KRAEMER, 1999). Essa inadequação se deve, no caso das empresas modernas (BORNIA, 2010), ao aumento da representatividade dos custos indiretos de fabricação (CIF) no custo total e à redução da participação de materiais e mão de obra nesse custo (KRAEMER, 1999).

No entanto, como comenta Kraemer (1999), as diferentes tentativas de desenvolver sistemas que propiciem o devido suporte à tomada de decisões têm apresentado uma abrangência parcial, contemplando apenas parte do processo produtivo e das reais necessidades de informações. Assim, não se consegue responder adequadamente a questões de definição de preços e de mix de produtos, sendo pertinente a seguinte pergunta: 'em que circunstâncias o uso do custeio ABC é indicado?'. Alguns autores (KHOURY e ANCELEVICZ, 2000; McARTHUR, 1993; HOLMEN, 1995, BORNIA, 2010) sugerem que o ABC é adequado para decisões de longo prazo. No entanto, não consideram que, muitas vezes, não é possível fazer uma distinção clara entre o que seriam decisões de curto e de longo prazo e, além disso, algumas decisões de curto prazo podem gerar conseqüências no longo prazo, conforme argumentam Bakke e Hellberg (1991). Nessa mesma linha, Kee e Schmidt (2000) mencionam que quando o excesso de capacidade não pode ser redistribuído ou eliminado, as decisões de mix de produtos utilizando-se o $A B C$ podem ser subótimas mesmo no longo prazo.

Percebe-se, portanto, que não há unanimidade quanto à eliminação pelo $\mathrm{ABC}$ dos erros $\mathrm{e}$ distorções do método dos Centros de Custos. Portanto, a definição da ferramenta a ser utilizada deve ser feita caso a caso, considerando-se, entre outros fatores, aspectos como: i) as particularidades da empresa; ii) a composição de seus custos; iii) o horizonte de tempo; iv) o poder de gestão sobre a mão-de-obra e sobre a capacidade da empresa; v) a complexidade da solução a ser adotada; vi) os investimentos necessários; vi) as necessidades de treinamentos específicos; e vii) a cultura organizacional. Os quatro últimos itens estão diretamente ligados à dificuldade de implantação do ABC.

Com o objetivo de reduzir o tempo gasto na implantação, atualização e operacionalização do método ABC, foi criado o TDABC, o qual tem como principal característica facilitar a identificação de custos através do uso de equações de tempo. Em linhas gerais, pode-se dizer que o TDABC diferencia-se do ABC tradicional por sua facilidade de implantação. Para Kaplan e Anderson (2007), o TDABC simplifica o processo de custeio ao eliminar as pesquisas e entrevistas com os colaboradores que são necessárias no $\mathrm{ABC}$ para a alocação dos recursos às atividades e posterior rateio entre os produtos.

O TDABC utiliza o tempo para direcionar os custos dos recursos diretamente a objetos como transações, pedidos, produtos, serviços e clientes. Para tanto, utiliza equações de tem $\neg$ po que, de maneira direta e automática, distribuem os custos às atividades executadas e às transações 
processadas. Apenas dois parâmetros precisam ser estimados: i) a taxa do custo da capacidade para o departamento; e ii) o uso da capacidade por transação processada no departamento. Segundo Kaplan e Anderson (2007), ambos os parâmetros podem ser estimados com facilidade e objetividade.

O TDABC ignora a fase de definição das atividades, eliminando a necessidade de alocar os custos dos departamentos entre as várias atividades por eles executadas. Assim, sua aplicação evita o trabalho dispendioso, demorado e subjetivo de pesquisa de atividades do ABC convencional.

Já o método da Unidade de Esforço de Produção (UEP), segundo Bornia (2010), originou-se na França, na época da Segunda Guerra Mundial, onde o engenheiro francês, Georges Perrin, criou um método de cálculo, alocação de custos e controle de gestão denominado GP. Após a morte de Perrin, sua metodologia caiu em esquecimento, sendo posteriormente retomada por Franz Allora, que a trouxe ao Brasil no início dos anos 60, a modificou e passou a chamá-la de método das UPs ou UEPs. Sua efetiva aplicação teve início a partir de 1978 com a implantação deste sistema de custos em cerca de 30 empresas da região de Blumenau e Joinville (BORNIA, 2010).

Em 1986, uma equipe de pesquisadores da Universidade Federal de Santa Catarina (UFSC) incumbiu-se de estudar, divulgar e aprimorar o método, de onde se deu a efetiva divulgação do mesmo em congressos e por meio de dissertações de mestrado. Após isso, muitos trabalhos surgiram, principalmente na UFSC e na Universidade Federal do Rio Grande do Sul (UFRGS), e atualmente cerca de 120 empresas do Paraná, São Paulo, Santa Catarina e Rio Grande do Sul utilizam o método (BORNIA, 2010).

A UEP considera em sua implantação os seguintes procedimentos: i) divisão da fábrica em postos operativos; ii) cálculo dos índices de custos onde não são incluídos o custo de matéria prima e as despesas de estrutura; iii) escolha do produto base; iv) cálculo dos potenciais produtivos; e v) determinação dos equivalentes dos produtos. Já em sua operacionalização destacam-se: i) a mensuração da quantidade produzida; ii) o cálculo dos custos de transformação; e iii) a elaboração de medidas de desempenho.

A UEP considera como princípio de implantação o custeio integral, uma vez que todos os gastos, incluindo perdas normais e anormais, são alocados à produção do período. No entanto, a operacionalização do método pode ser adaptada para o custeio por absorção parcial (padrão de desempenho considerando perdas normais) ou ideal, conforme sugere Bornia (2010).

O método da UEP mensura produtos diferentes e que não são aparentemente comparáveis entre si através da noção de esforço de produção. O foco da UEP recai exclusivamente sobre os custos de transformação, não gerando informações sobre processos e custos de apoio. O método permite uma complementação da informação da margem de contribuição, agregando os custos de transformação. 
A UEP pode ser considerada complementar ao método dos Centros de Custos e ao $\mathrm{ABC}$, sendo a primeira utilizada nas atividades de fabricação e os dois últimos nas atividades de apoio. Percebe-se, também, uma complementaridade entre os métodos custo-padrão, UEP e ABC, sendo o primeiro indicado para os custos de matéria prima e eventualmente mão de obra direta (MOD), o segundo para as áreas produtivas (onde o nível de detalhamento deve ser maior) e o terceiro para as áreas de apoio (despesas de estrutura). Além disso, o método dos Centros de Custos (consideradas suas limitações) pode ser utilizado alternativamente ao ABC e à UEP ou servir de base para a aplicação dos mesmos.

Em uma comparação com o TDABC, enquanto este calcula a distribuição dos custos (ou gastos) totais do período a partir da verificação das horas padrão de trabalho, o método da UEP constrói essa taxa, tentando identificar o real consumo dos recursos para certa unidade de tempo. Seguindo nessa linha, pode-se dizer que o método da UEP aprovisiona os custos das atividades diretas e rateia os custos das atividades indiretas, enquanto que o método TDABC utiliza-se apenas de rateio para todas as atividades, independentemente de uma eventual facilidade de atribuição direta. O método da UEP, como aprovisiona e não rateia recursos, consegue trabalhar com mais facilidade e segurança em níveis de estratificação mais agudos, o que lhe acaba conferindo maior acuracidade nos resultados finais. Uma vez que o método TDABC considera um tempo padrão de execução de cada departamento, ele acaba desconsiderando o fato de que o tempo real trabalhado pode ser menor que o tempo padrão pré-estabelecido, ocasionando uma inadequada distribuição de uma parcela dos custos variáveis. Finalmente, a estrutura lógica do método da UEP realiza uma ponderação entre o valor dos postos operativos, seu grau de eficiência e seu grau de utilização, consolidando essas informações em um único índice final, o qual ainda pode ser desdobrado por departamento, se for de interesse para a análise. O método TDABC não proporciona essa possibilidade, o que prejudica uma análise consolidada da eficiência de uma organização.

\section{Aplicabilidade dos métodos de custeio à empresa estudada}

Este capítulo tem como objetivo avaliar a aplicabilidade dos diferentes métodos de custeio discutidos anteriormente à empresa em estudo. Para tanto, primeiramente são apresentadas as características gerais da empresa e do setor a que pertence. A partir dessas características, é feito um diagnóstico da organização orientado a alguns fatores relevantes para a definição do método de custeio mais adequado. Finalmente, tendo como base o referencial teórico sobre sistemas de custos, bem como a caracterização da empresa e o diagnóstico efetuado, é elaborado um mapa conceitual para apoiar a análise da aplicabilidade dos diferentes métodos de custeio à organização. 


\subsection{Características gerais da empresa e do setor}

O estudo foi realizado em uma empresa de pequeno porte, localizada em Carlos BarbosaRS, que atua no setor de transformados plásticos. Segundo o Moreira et al. (2010), o setor de transformados plásticos no Brasil é intensivo em mão-de-obra, possuindo intensidade tecnológica média-baixa. Atua nesse setor um grande número de empresas de porte reduzido, as quais atendem a mercados muito distintos, com um padrão de competição freqüentemente baseado em preços. Devido às pressões exercidas por fornecedores e clientes, tais empresas se vêem pressionadas a reverem seus custos e, na impossibilidade disso, reduzirem suas margens de lucro.

Atuante nesse setor desde sua fundação (março de 2002), a empresa estudada possui uma estrutura organizacional enxuta e atua com um mix composto por apenas sete produtos licenciados de clubes de futebol: i) caneca standard; ii) mini caneca standard; iii) mugball (caneca em formato de bola de futebol); iv) mini mugball (igual ao item anterior, porém em tamanho reduzido); v) copo térmico; vi) beerball (porta-garrafa de cerveja em formato de bola de futebol); e vii) porta latas/garrafas long neck. Atualmente, a produção de $100 \%$ dos itens é terceirizada, ficando por conta da empresa atividades como pesquisa e desenvolvimento de produtos, marketing, vendas e departamento de pessoal, além dos serviços de contabilidade, publicidade, tecnologia de informação e logística. A dependência em relação aos fornecedores, associada à localização dos clientes em diferentes estados do Brasil e à condição de vendas Cost, Insurance and Freight (CIF) utilizada pela empresa, a qual determina que os fretes são por sua conta, torna crítica a gestão da cadeia de suprimentos (Figura 1) para a competitividade da organização.

Figura 1 - Cadeia de suprimentos da empresa estudada

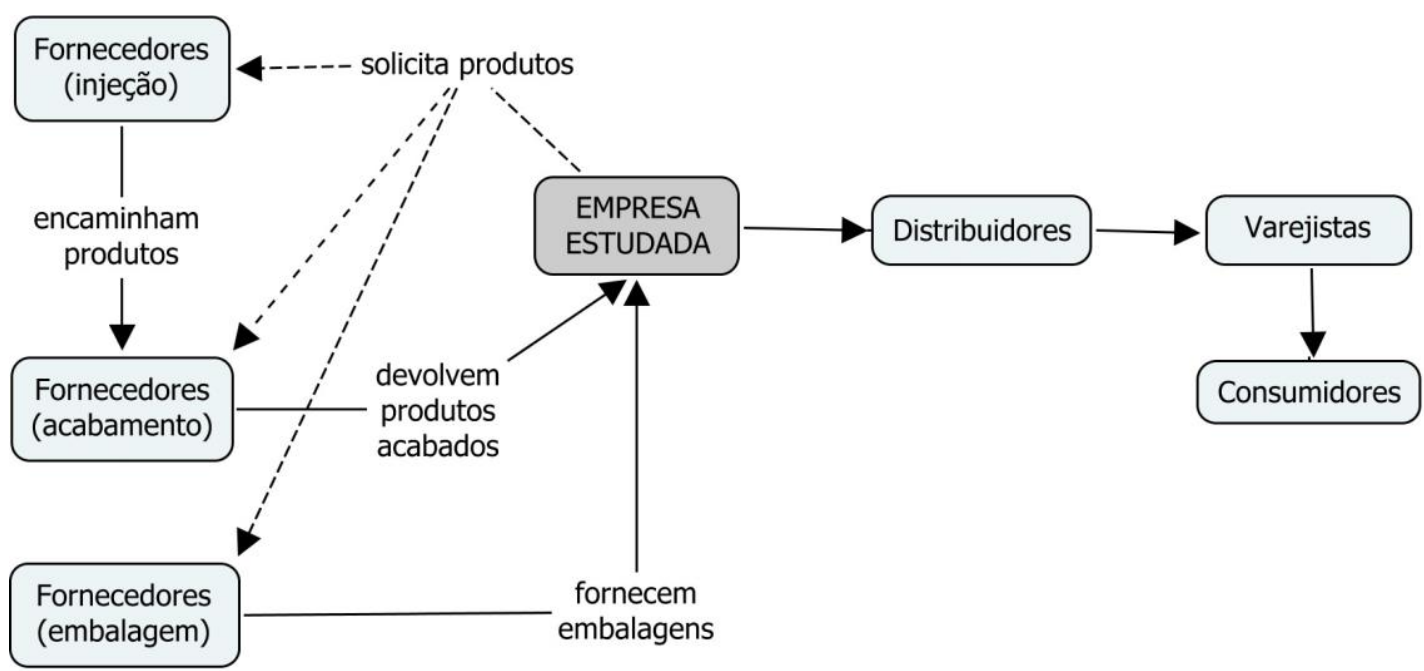

Fonte: Elaborada a partir de informações da organização

Atualmente, a empresa possui doze distribuidores espalhados pelo Brasil que pulverizam os produtos em atacados, pequenas lojas licenciadas e redes de supermercados. Além disso, há cinco representantes que atuam em estados onde ainda não há distribuidores. 
Quanto à dinâmica da cadeia de suprimentos apresentada na Figura 1, a empresa é responsável pela retirada dos produtos injetados do fabricante terceirizado, pela entrega no terceiro que fará a impressão gráfica e pela posterior retirada do produto acabado. Os custos de transporte são de responsabilidade da empresa estudada. A organização possui três fornecedores responsáveis pela injeção dos produtos (dois deles estão localizadas em Caxias do Sul e um em Bento Gonçalves), dois responsáveis pelo acabamento (sediados em Caxias do Sul) e um fornecedor de embalagens (localizado em Caxias do Sul). O processo de embalagem é integralmente feito pela empresa estudada.

No que se refere aos preços de venda, a empresa trabalha com quatro tabelas distintas, conforme a região: i) Região Sul; ii) Regiões Sudeste e Centro-Oeste; iii) Região Nordeste; e iv) Região Norte. A tabela de preços é formada na condição CIF, sendo estabelecida uma quantidade mínima a ser adquirida. Abaixo dessa quantidade, o frete torna-se responsabilidade do cliente (condição Free on Board - FOB). A tabela de preços é revisada anualmente, uma vez que a empresa busca reduzir seus custos em função da melhoria nos processos de fabricação e da renegociação com seus fornecedores.

A complexidade da cadeia de suprimentos da empresa, especialmente no que se refere à logística de distribuição (com fretes, volumes, mix de produtos e destinos variáveis) e ao faturamento empenhado em poucos itens, faz necessária a identificação de quais produtos e clientes são mais ou menos rentáveis para a organização, com vistas a estabelecer estratégias para o aumento de sua competitividade, justificando, portanto, a (re)avaliação do método de custeio mais adequado. Para tanto, antes é necessário um diagnóstico da empresa, dando ênfase nos fatores que auxiliem a identificação do método de custeio mais apropriado para a mesma.

\subsection{Diagnóstico da empresa}

Para auxiliar na análise dos métodos de custeio adequados à organização, foi feito um diagnóstico da mesma, o qual é apresentado na Figura 2. O diagnóstico considerou três dimensões gerais (ambiente competitivo, estrutura organizacional e processos), cada uma delas composta por alguns fatores, os quais foram subdivididos em características. O diagnóstico consistiu em identificar em cada fator a característica que melhor definia a situação da empresa, conforme avaliação dos diretores. 
Figura 2 - Diagnóstico da empresa

\begin{tabular}{|c|c|c|c|c|}
\hline Dimensão & Fator & Características & Diag. & Justificativa \\
\hline \multirow{10}{*}{$\begin{array}{l}\text { Ambiente } \\
\text { Competitivo }\end{array}$} & \multirow{4}{*}{$\begin{array}{l}\text { Grau de } \\
\text { incerteza no } \\
\text { mercado }\end{array}$} & Muito alto & & \multirow{4}{*}{$\begin{array}{l}\text { O ambiente externo é relativamente previsível, } \\
\text { pelo negócio estar focado no futebol. O esporte é } \\
\text { amplamente difundido no país e não há } \\
\text { indicadores de mudanças significativas no cenário } \\
\text { de médio e longo prazo. }\end{array}$} \\
\hline & & Alto & & \\
\hline & & Médio & & \\
\hline & & Baixo & $X$ & \\
\hline & \multirow{3}{*}{$\begin{array}{l}\text { Pressões } \\
\text { competitivas }\end{array}$} & Intensas & & \multirow{3}{*}{$\begin{array}{l}\text { As maiores pressões encontram-se no poder de } \\
\text { barganha dos fornecedores, nos produtos } \\
\text { substitutos e na pirataria. A rivalidade é diminuída } \\
\text { pelo licenciamento do uso das marcas dos times. }\end{array}$} \\
\hline & & Moderadas & $\mathrm{X}$ & \\
\hline & & Fracas & & \\
\hline & \multirow{3}{*}{$\begin{array}{l}\text { Necessidade } \\
\text { de ganhos } \\
\text { imediatos }\end{array}$} & Alta & & \multirow{3}{*}{$\begin{array}{l}\text { A liquidez e o endividamento fazem com que a } \\
\text { empresa necessite de ciclos operacionais curtos, } \\
\text { principalmente pela escassez de capital circulante } \\
\text { líquido e capital de giro próprio. }\end{array}$} \\
\hline & & Média & $\mathrm{X}$ & \\
\hline & & Baixa & & \\
\hline \multirow{20}{*}{$\begin{array}{l}\text { Estrutura } \\
\text { Organiza- } \\
\text { cional }\end{array}$} & \multirow{3}{*}{$\begin{array}{l}\text { Tipo de } \\
\text { operações }\end{array}$} & Industriais & & \multirow{3}{*}{$\begin{array}{l}\text { Como a empresa tem sua produção totalmente } \\
\text { terceirizada, suas operações se assemelham à de } \\
\text { uma empresa comercial. }\end{array}$} \\
\hline & & Comerciais & $\mathrm{X}$ & \\
\hline & & Serviços & & \\
\hline & \multirow{2}{*}{$\begin{array}{l}\text { Tipo de } \\
\text { Estrutura }\end{array}$} & Simples & $X$ & \multirow{2}{*}{$\begin{array}{l}\text { A empresa funciona em regime de outsourcing, } \\
\text { com estrutura operacional e de apoio enxutas. }\end{array}$} \\
\hline & & Complexa & & \\
\hline & \multirow{3}{*}{$\begin{array}{l}\text { Possibilidade } \\
\text { de adequação } \\
\text { da estrutura } \\
\text { organizacional }\end{array}$} & Alta & $X$ & \multirow{3}{*}{$\begin{array}{l}\text { Em virtude da logística, além de diversas } \\
\text { atividades de apoio serem terceirizadas, a } \\
\text { estrutura organizacional possui grande } \\
\text { flexibilidade e boa adaptabilidade. }\end{array}$} \\
\hline & & Média & & \\
\hline & & Baixa & & \\
\hline & \multirow{3}{*}{$\begin{array}{l}\text { Cultura } \\
\text { organizacional }\end{array}$} & Favorável & $\mathrm{X}$ & \multirow{3}{*}{$\begin{array}{l}\text { A empresa tem uma cultura favorável à mudança e } \\
\text { à implantação de projetos de melhoria, } \\
\text { especialmente devido à visão dos gerentes/ } \\
\text { proprietários. }\end{array}$} \\
\hline & & Intermediária & & \\
\hline & & Desfavorável & & \\
\hline & \multirow{3}{*}{$\begin{array}{l}\text { Capacitação } \\
\text { dos } \\
\text { colaboradores }\end{array}$} & Favorável & & \multirow{3}{*}{$\begin{array}{l}\text { O capital humano da empresa para a condução de } \\
\text { projetos de melhoria é escasso e a capacitação de } \\
\text { pessoal restringe-se à gerência. }\end{array}$} \\
\hline & & Intermediária & $X$ & \\
\hline & & Desfavorável & & \\
\hline & \multirow{3}{*}{$\begin{array}{l}\text { Fator de maior } \\
\text { impacto nos } \\
\text { custos }\end{array}$} & Matéria prima & & \multirow{3}{*}{$\begin{array}{l}\text { Os custos relacionados às compras e aos estoques } \\
\text { da empresa são os de maior impacto nos preços de } \\
\text { venda. Em segundo lugar de importância estão os } \\
\text { custos indiretos. }\end{array}$} \\
\hline & & $\begin{array}{l}\text { Custos de } \\
\text { Produção }\end{array}$ & $\mathrm{X}$ & \\
\hline & & $\begin{array}{l}\text { Custos Ind. de } \\
\text { Fabricação }\end{array}$ & & \\
\hline & \multirow{3}{*}{\begin{tabular}{|l|} 
Capacidade de \\
investimento \\
em projetos de \\
melhoria \\
\end{tabular}} & Alta & & \multirow{3}{*}{$\begin{array}{l}\text { A empresa não dispõe de recursos financeiros para } \\
\text { investimentos em projetos de melhoria e/ou ainda } \\
\text { não encontra expertise necessária para transformar } \\
\text { esses investimentos em rentabilidade. }\end{array}$} \\
\hline & & Média & $X$ & \\
\hline & & Baixa & & \\
\hline
\end{tabular}




\begin{tabular}{|c|c|c|c|c|}
\hline Dimensão & Fator & Características & Diag. & Justificativa \\
\hline \multirow{23}{*}{ Processos } & \multirow[b]{2}{*}{$\begin{array}{l}\text { Fluxo de } \\
\text { trabalho }\end{array}$} & Irregular & & \multirow{2}{*}{$\begin{array}{l}\text { O fluxo de trabalho interno, embora não seja } \\
\text { mapeado, pode ser considerado repetitivo. No } \\
\text { entanto, as atividades de distribuição apresentam } \\
\text { significativa irregularidade e complexidade. }\end{array}$} \\
\hline & & $\begin{array}{l}\text { Definido/ } \\
\text { Repetitivo }\end{array}$ & $X$ & \\
\hline & \multirow{3}{*}{$\begin{array}{l}\text { Complexidade } \\
\text { dos processos }\end{array}$} & Alta & & \multirow{3}{*}{$\begin{array}{l}\text { Em função da terceirização, não há muita } \\
\text { complexidade na estrutura organizacional e nos } \\
\text { processos internos. Porém, a localização dos } \\
\text { clientes e a condição de venda "CIF" tornam a } \\
\text { distribuição complexa e relevante. }\end{array}$} \\
\hline & & Média & $X$ & \\
\hline & & Baixa & & \\
\hline & \multirow{3}{*}{$\begin{array}{l}\text { Custos de } \\
\text { complexidade }\end{array}$} & Altos & & \multirow{3}{*}{$\begin{array}{l}\text { O mix de produtos da empresa é pequeno, os } \\
\text { produtos são padronizados e a customização se dá } \\
\text { apenas no acabamento. No entanto, a abrangência } \\
\text { do mix (diferentes clubes de futebol) afeta o } \\
\text { atendimento ao mercado (distribuição). }\end{array}$} \\
\hline & & Médios & $\mathrm{X}$ & \\
\hline & & Baixos & & \\
\hline & \multirow{4}{*}{$\begin{array}{l}\text { Situação dos } \\
\text { processos }\end{array}$} & $\begin{array}{l}\text { Desconhecidos/ } \\
\text { informais }\end{array}$ & $X$ & \multirow{4}{*}{$\begin{array}{l}\text { A empresa tem como uma de suas fraquezas no } \\
\text { ambiente interno a falta de mapeamento e } \\
\text { gerenciamento de seus processos. }\end{array}$} \\
\hline & & Mapeados & & \\
\hline & & $\begin{array}{l}\text { Mapeados e } \\
\text { padronizados }\end{array}$ & & \\
\hline & & $\begin{array}{l}\text { Mapeados, } \\
\text { padronizados e } \\
\text { frequentemente } \\
\text { reavaliados }\end{array}$ & & \\
\hline & \multirow{3}{*}{$\begin{array}{l}\text { Cálculo e } \\
\text { análise de } \\
\text { custos }\end{array}$} & $\begin{array}{l}\text { Expandidos por } \\
\text { toda a empresa e } \\
\text { integrados }\end{array}$ & & \multirow{3}{*}{$\begin{array}{l}\text { A análise e o gerenciamento dos custos } \\
\text { concentram-se na gerência administrativa da } \\
\text { empresa. }\end{array}$} \\
\hline & & $\begin{array}{l}\text { Concentrados em } \\
\text { um ou poucos } \\
\text { departamentos }\end{array}$ & $X$ & \\
\hline & & $\begin{array}{l}\text { Efetuados } \\
\text { externamente ou } \\
\text { não realizados } \\
\end{array}$ & & \\
\hline & \multirow{2}{*}{$\begin{array}{l}\text { Compra de } \\
\text { matéria prima }\end{array}$} & $\begin{array}{l}\text { Efetuada pela } \\
\text { empresa }\end{array}$ & & \multirow{2}{*}{$\begin{array}{l}\text { A compra das matérias primas necessárias à } \\
\text { produção é feita diretamente pelos fornecedores, } \\
\text { sem qualquer intervenção da empresa. }\end{array}$} \\
\hline & & $\begin{array}{l}\text { Efetuada pelos } \\
\text { fornecedores }\end{array}$ & $X$ & \\
\hline & \multirow{3}{*}{$\begin{array}{l}\text { Representativi } \\
\text { dade dos } \\
\text { custos } \\
\text { indiretos (de } \\
\text { estrutura) nos } \\
\text { custos totais }\end{array}$} & Alta & & \multirow[b]{3}{*}{$\begin{array}{l}\text { Os custos indiretos representam cerca de } 30 \% \text { dos } \\
\text { custos totais. Os custos de compra são os mais } \\
\text { importantes, representando os } 70 \% \text { restantes. }\end{array}$} \\
\hline & & Média & $\mathrm{X}$ & \\
\hline & & Baixa & & \\
\hline & \multirow{3}{*}{$\begin{array}{l}\text { Necessidade } \\
\text { de } \\
\text { detalhamento } \\
\text { de indicadores }\end{array}$} & Alta & $\mathrm{X}$ & \multirow{3}{*}{$\begin{array}{l}\text { Como o mix de produtos é pequeno, a } \\
\text { rentabilidade da empresa está empenhada em } \\
\text { poucos itens que, se não monitorados de modo } \\
\text { eficaz, podem gerar problemas financeiros. }\end{array}$} \\
\hline & & Média & & \\
\hline & & Baixa & & \\
\hline
\end{tabular}

Fonte: Os autores 
A partir do diagnóstico efetuado, percebe-se que a empresa se encontra em um ambiente competitivo caracterizado por pressões moderadas. $\mathrm{O}$ fato de as pressões não serem maiores se deve, principalmente, ao 'valor' dos produtos ofertados pela organização, o qual reside no seu simbolismo e não na funcionalidade em si. Woodruff (1997) conceitua valor para o consumidor como uma preferência percebida sobre os atributos do produto e as conseqüências que advém do uso. Já Cobra (2005) discorre sobre a importância do caráter simbólico dos produtos na percepção do valor. Segundo o autor, o produto tem maior valor para o consumidor pelo caráter simbólico intangível do que por suas características tangíveis. Nesse sentido, pode-se dizer que a percepção dos clientes da empresa quanto ao benefício auferido encontra-se calcada na oficialidade outorgada ao produto pelo licenciamento e uso da marca do clube de futebol para que 'torcem'. Os produtos são atrativos devido à diferença entre o valor percebido pelos consumidores (torcedores dos clubes de futebol licenciados pela empresa) e o custo despendido pela aquisição da mercadoria.

No que se refere à estrutura organizacional, pode-se dizer que a terceirização confere certa simplicidade à organização, sendo a mesma considerada um exemplo híbrido entre indústria e empresa comercial. Outras características relevantes são a possibilidade de adequação da estrutura e a cultura favorável à implantação de projetos de melhoria. Quanto aos métodos de custeio, a empresa atualmente utiliza o método dos Centros de Custos, devido à sua simplicidade, mesmo sabendo que o mesmo pode gerar distorções, dependendo da estrutura da empresa, complexidade do negócio e métodos de rateio utilizados.

No que diz respeito aos processos, embora as atividades internas sejam relativamente simples, há uma considerável complexidade na cadeia de suprimentos (BOWERSOX e CLOSS, 2001; DORNIER et al, 2000), em especial no que se refere à movimentação dos produtos dos locais de produção aos pontos de venda ou logística de distribuição (HESSE e RODRIGUE, 2004). Embora os custos de aquisição dos produtos sejam os mais importantes para a empresa, os custos indiretos têm relevante impacto, representando aproximadamente $30 \%$ dos custos totais. Isso faz com que rateios arbitrários desses custos gerem significativas distorções, o que justifica a análise da aplicabilidade dos diferentes métodos de custeio à organização.

\subsection{Análise da possível aplicabilidade dos métodos de custeio}

A partir da revisão da literatura e da caracterização e diagnóstico da empresa estudada, foi elaborado o mapa conceitual apresentado na Figura 3, o qual demonstra a aplicabilidade dos diferentes métodos de custeio à organização.

O mapa conceitual desenvolvido, para sua devida compreensão, deve ser analisado "de fora para dentro", considerando primeiramente os fatores, seguidos pelas características encontradas na empresa e pelos métodos de custeio analisados. Tanto os fatores como as características 
apresentadas na Figura 3 são oriundos do diagnóstico (Figura 2). No entanto, foram eliminados alguns pontos excessivamente detalhados, os quais, apesar de serem importantes para o diagnóstico, mostraram-se desnecessários na análise da aplicabilidade dos métodos de custeio à empresa, onde se busca maior objetividade e visão da situação como um todo. Assim, os dezessete fatores apresentados no diagnóstico (Figura 2) foram reduzidos a nove. A dimensão 'ambiente competitivo' foi apresentada como um todo, em um único fator. Já as dimensões 'estrutura organizacional' e 'processos' foram detalhadas em quatro fatores cada.

A partir da análise da Figura 3, percebe-se que o uso dos métodos do custo padrão e das UEPs não são indicados para a empresa, podendo-se aplicar o método dos Centros de Custos (já utilizado pela organização) ou, alternativamente, o custeio ABC ou o TDABC.

Figura 3 - Aplicabilidade dos métodos de custeio à empresa estudada

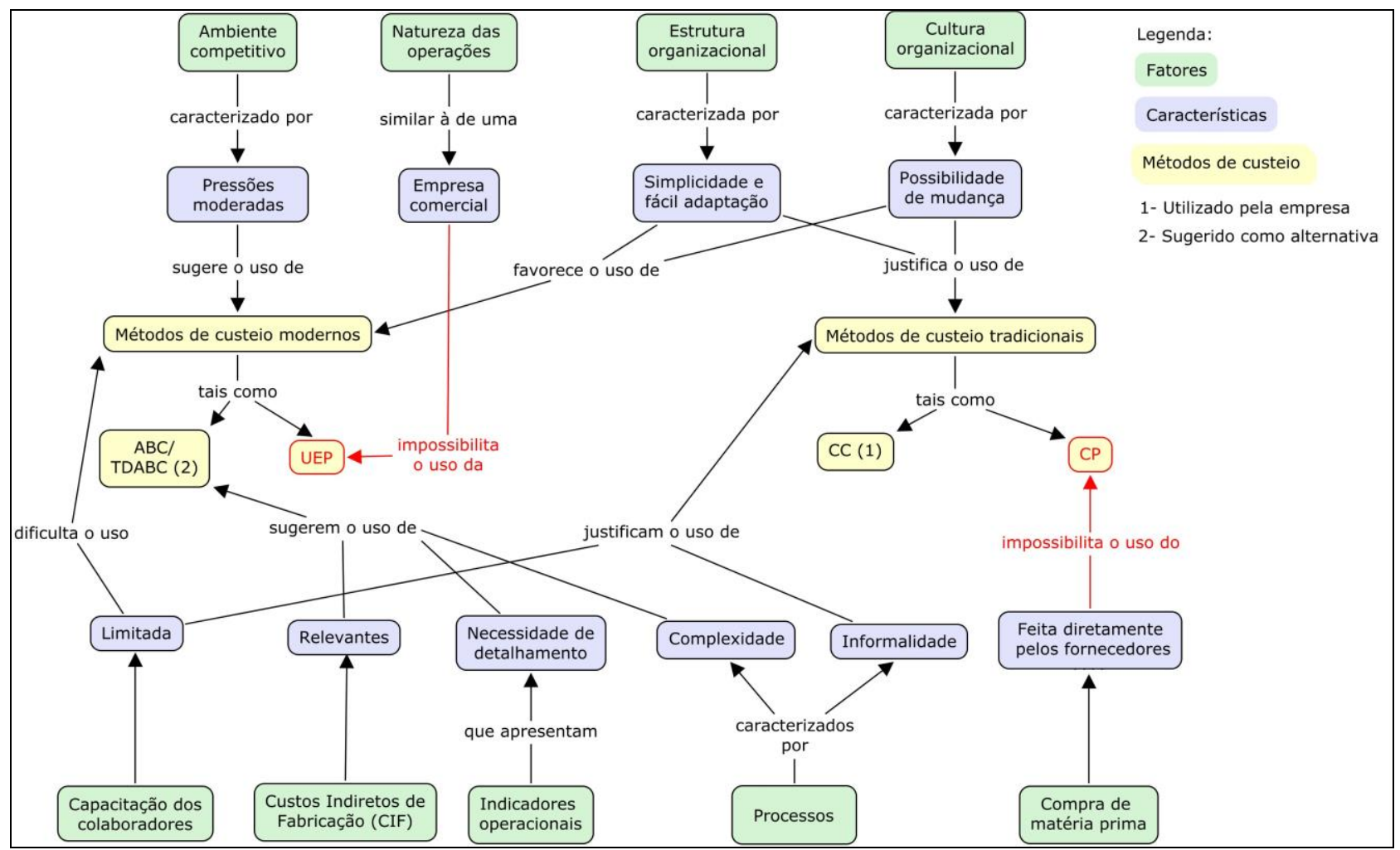

Fonte: Os autores

Identificados os métodos de custeio aplicáveis à empresa, é necessário avaliar os prós e contras dos mesmos. Nesse sentido, é analisado o método dos Centros de Custos comparativamente ao $\mathrm{ABC}$ e este último em relação ao TDABC.

O método dos Centros de Custos hoje é utilizado pela empresa basicamente como ferramenta para distribuição dos custos indiretos aos produtos. Os centros refletem a estrutura vertical da organização e os custos são atribuídos a eles, mesmo apresentando atividades heterogêneas, o que gera distorções, além de não possibilitar uma análise do processo como um todo e a identificação de perdas. Já o método ABC, apesar de mais complexo, proporciona uma 
visão horizontal e contribui para análises aprofundadas do fluxo de atividades por apresentar um elevado nível de detalhamento das mesmas.

O sistema atual baseado nos Centros de Custos pode servir de base para a implementação do ABC. Com o custeio ABC, as exigências diferenciadas que os objetos fazem da estrutura da empresa (custos da complexidade) podem ser identificadas e, a partir de bases de alocação ou de relação (cost drivers - direcionadores de custos), podem ser relacionados os recursos engajados às atividades e estas aos objetos. Um dos principais benefícios do $\mathrm{ABC}$ é a reestruturação e mapeamento dos gastos funcionais (departamentais) para mostrar como se relacionam com processos e atividades.

Já o TDABC, por ser uma simplificação do método ABC, também poderia ser utilizado pela empresa. Com a utilização do mesmo, poderia ser reduzido o trabalho dispendioso necessário à implantação do ABC convencional. No entanto, no caso estudado, por se tratar de uma empresa com estrutura enxuta e mix de produtos reduzido, acredita-se que a coleta de dados para a implementação do método $\mathrm{ABC}$ não seja tão trabalhosa, ainda mais partindo-se dos centros de custos já estruturados. Portanto, no caso estudado, o TDABC não representa grandes vantagens frente ao $\mathrm{ABC}$ tradicional, o qual proporcionaria maiores níveis de detalhamento e controle para a empresa.

\section{Considerações finais}

Altos graus de competitividade têm exigindo uma postura pró-ativa das organizações pela contínua melhoria de desempenho e reduções de custos. Um sistema de custeio bem adaptado às necessidades organizacionais tem condições de fornecer embasamento para tomadas de decisão de curto, médio e longo prazo, dependo das circunstâncias. Particularidades dos mercados e estruturas corporativas exigem um estudo aprofundado da empresa antes da definição do método a ser implementado.

Este artigo apresentou uma revisão dos sistemas de custos através de um estudo dos diferentes princípios e métodos de custeio (tradicionais e modernos), bem como a avaliação de sua aplicabilidade à empresa estudada, consideradas as limitações decorrentes das características da organização, especialmente a produção terceirizada.

Com as análises efetuadas, constatou-se que seria viável a manutenção do método dos Centros de Custos (atualmente utilizado pela empresa), o que - no entanto - não resultaria em ganhos adicionais de informação e controle, como pretendido pela organização. Assim, alternativamente, foi proposto à empresa a implementação dos métodos $\mathrm{ABC}$ ou TDABC, sendo este último uma simplificação do primeiro e aquele indicado para um maior detalhamento dos processos. 


\begin{abstract}
The increasingly competition among companies impose a constant re-evaluation of the internal processes aiming to increase efficiency and reduce costs. In this environment costing method definition has great relevance. Given all the complexity inherent to certain costing methods implementation, it is previously necessary a critical analysis of the company in order to verify the possible adequacy of each method. The present paper has as objective identify the costing methods indicated to a company that has outsourced production. The studied organization currently uses the method of "Cost Centers" and due to some distortions arising from the fundaments of the method wants to evaluate the possible use of alternative costing methods. In this sense the paper presents a review on costing systems, detailing the different principles and costing methods (traditional and modern) and analyzing its applicability to the studied company. The results indicate the applicability of the Cost Centers method, currently used by the company and alternatively suggest the use o ABC or TDABC costing to better identify service cost to the different customers.
\end{abstract}

Keywords: costing methods; comparative analysis; company with outsourced production.

\title{
Referências
}

BAKKE, N.; HELLBERG, R. Relevance lost? A critical discussion of different cost accounting principles in connection with decision making for both short and long term production scheduling. International Journal of Production Economics, v. 24, n. 2, p. 1-18, 1991. crossref

BEBER, S.; SILVA, E.; DIÓGENES, M; KLIEMANN NETO, F. J. Princípios de custeio: uma nova abordagem. Anais do XXIV Encontro Nacional de Engenharia de Produção (ENEGEP). Florianópolis, 2004.

BORNIA, A. C. Análise Gerencial de Custos: Aplicação em empresas modernas. São Paulo: Atlas, 2010.

BOWERSOX, D. J.; CLOSS, D. J. Logística empresarial: o processo de integração da cadeia de suprimento. São Paulo: Atlas, 2001

CAMPAGNOLO, R. R.; SOUZA, J. S.; KLIEMANN NETO, F. J. Seria mesmo o Time-Driven ABC (TDABC) um método de custeio inovativo? Uma análise comparativa entre o TDABC e o método da Unidade de Esforço de Produção (UEP). XI Congreso Internacional de Costos y Gestión. Trelew, Chubut, Patagônia Argentina, setembro de 2009.

CATELLI, A. Controladoria: Uma abordagem da Gestão Econômica (GECON). 2. ed. São Paulo: Atlas, 2001.

COBRA, M. H. N. Administração de Marketing no Brasil. 2. ed. São Paulo: Cobra Editora e Marketing, 2005.

COOPER, R.; KAPLAN, R. S. How Cost Accounting Distorts Product Costs. Management Accounting, v. 69, n. 10, p. $20-27,1988$.

DORNIER, P.; ERNST, R.; FENDER, M.; KOUVELIS, P. Logística e operações globais - texto e casos. São Paulo: Atlas, 2000.

GOLDRATT, E.; COX, J. A Meta: Um processo de melhoria contínua. São Paulo: Educator, 1984.

HESSE, M.; RODRIGUE, J. P. The transport geography of logistics and freight distribution. Journal of Transport Geography, n. 12, p. 171-184, 2004. crossref

HOLMEN, J. ABC vs. TOS: It's a matter of time activity-based costing and the theory of constraints can work together. Management Accounting, v.76, n.1, p.37-40, 1995.

KAPLAN, Robert. In defense of Activity-Based Cost management. Management Accounting, p. 58-63, Nov. 1992.

KAPLAN, R.; ANDERSON, S. R. Time-Driven Activity-Based Costing: A Simpler and More Powerful Path to Higher Profits. Harvard Business School Publishing, 2007.

KEE, R.; SCHMIDT, C. A comparative analysis of utilizing activity-based costing and the theory of constraints for making product-mix decisions. International Journal of Production Economics, v. 63, n. 1, p.1-17, 2000. crossref 
KHOURY, C. Y.; ANCELEVICZ, J. Controvérsias acerca do sistema de custos ABC. Revista de Administração de Empresas (RAE), v. 40, n.1, p. 56-62, 2000. crossref

KNOLSEISEN, P. C. Compatibilização de orçamento com o planejamento do processo de trabalho para obras de edificações. Florianópolis: PPGEP/UFSC, 2003. Dissertação (Mestrado em Engenharia de Produção).

KRAEMER, M. E. P. Contabilidade Gerencial - uma necessidade de mudança operacional. Contabilidade Vista \& Revista, v. 10, n.2, p. 42-50, 1999.

McARTHUR, J. Theory of Constraints and activity-based costing: Friends or foes? Journal of Cost Management, v.7, n.2, p.50-56, 1993.

MOREIRA, C.; BASTOS, V. D.; GOMES, G. L.; COSTA, L. M.; KUME, L.; MAGALHÃES, B. A.; GLÓRIA, A. M. S. O apoio do BNDES ao setor de transformados plásticos. BNDES Setorial, Rio de Janeiro, v. 31, Plásticos, p. 99-146, mar. 2010.

MÜller, C. J. A Evolução dos Sistemas de Manufatura e as Mudanças nos Sistemas de Controle e Custeio. Porto Alegre: PPGEP/UFRGS, 1996. Dissertação de Mestrado em Engenharia de Produção.

PORTER, M. E. What is strategy? Harvard Business Review, p. 59-78, Nov-Dez 1996.

WOODRUFF, R. B. Customer value: the next source for competitive advantage. Journal of the Academy of Marketing Science, v. 25, n. 2, p. 139 - 153, 1997. cross ref

\section{Dados dos autores}

Nome completo: Guilherme Bergmann Borges Vieira

Filiação institucional: Universidade de Caxias do Sul (UCS)

Departamento: Centro de Ciências Sociais (CCSO)

Função ou cargo ocupado: Professor e pesquisador

Endereço completo para correspondência: Rua Francisco Getúlio Vargas, 1130 - CEP 95070-560 -

Caxias do Sul ? RS

Telefone para contato: (51) 9944-8504

e-mail: gbbvieir@ucs.br

\section{Nome completo: Bruna Homrich Aita}

Filiação institucional: Universidade Federal do Rio Grande do Sul (UFRGS)

Departamento: Programa de Pós-Graduação em Engenharia de Produção (PPGEP)

Função ou cargo ocupado: Ex-aluna do curso de Mestrado

Endereço completo para correspondência: Av. Nossa Senhora de Copacabana $n^{\circ}$ 80, ap. 604, CEP 22020-001, Rio de Janeiro - RJ

Telefone para contato: (21) 97522-6060

e-mail: bruna.aita@gmail.com

Nome completo: Francisco José Kliemann Neto

Filiação institucional: Universidade Federal do Rio Grande do Sul (UFRGS) 
Departamento: Programa de Pós-Graduação em Engenharia de Produção (PPGEP)

Função ou cargo ocupado: Professor e pesquisador

Endereço completo para correspondência: Av. Osvaldo Aranha, 99 - 5 Andar - Bairro Bom Fim CEP: 90035-190 - Porto Alegre - RS

Telefone para contato: (51) 3308-3545 e (51) 9915-7186

e-mail:kliemann@producao.ufrgs.br

Nome completo: Fabio Chies

Filiação institucional: Universidade de Caxias do Sul (UCS)

Departamento: Centro de Ciências Sociais (CCSO)

Função ou cargo ocupado: Ex-aluno de graduação

Endereço completo para correspondência: Rua Assis Brasil, 11 Centro ? CEP 95185-000 - Carlos Barbosa - RS

Telefones para contato: (54) 3461-4663 (res) / (54) 3461-8850 (com) / (54) 9954-8599 (cel)

e-mail: fabiochies@terra.com.br

Submetido em: 05/05/2014

Aceito em: 18/12/2014 